\title{
LA INTEGRACION SOCIAL Y ECONOMICA DE LOS INMIGRANTES ESPAÑOLES EN BRASIL*
}

HERBERT S. KLEIN

Columbia University

La gran ola de migraciones europeas y asiáticas que siguió a la abolición de la esclavitud en 1888 llevó hasta Brasil a unos cinco millones de inmigrantes nacidos en el extranjero. En este masivo movimiento migratorio, los inmigrantes españoles tuvieron un papel decisivo. Los tres cuartos de millón de españoles que fueron a Brasil en los setenta años comprendidos entre 1880 a 1950, participaron de forma notable en la expansión de la economía cafetera brasileña y, posteriormente, en la construcción de una gran economía urbana y agrícola en el Estado de São Paulo. Los españoles eran los terceros en importancia, tras italianos y portugueses, en toda la nación, pero debido a su concentración en São Paulo ocupaban el segundo lugar en este fundamental Estado. El ritmo de esta inmigración, como el de la italiana, estuvo del todo ligado a la demanda de mano de obra agrícola no especializada para los campos de café en expansión del planalto occidental, en el binterland de la ciudad de São Paulo. Con la deserción en masa de los 150.000 esclavos de las fazendas cafeteras paulistas, en proceso de ampliación, los fazenderos forzaron al Estado a iniciar la subvención de inmigrantes foráneos ', una labor que el gobierno federal acometió en los años siguientes, y que no se interrumpió hasta $1926^{2}$.

* Traducido por Eva Rodríguez Halfter.

José Francisco de Carmago (1981), p. 115. Este fue también el año en que se inició en São Paulo la famosa Hospedaria para alojar y registrar los datos de los inmigrantes llegados.

${ }^{2}$ Entre 1889 y 1929, un 57 por 100 de los inmigrantes extranjeros se dirigieron al Estado de São Paulo, y de ellos, un 45 por 100 recibió subvenciones para pagar su traslado desde Europa a las haciendas del interior. Thomas W. Merrick y Douglas H. Graham (1981), p. 125, cuadro 5.2. En las primeras dos décadas de esta migración masiva (o hasta 1900), estas cifras fueron, respectivamente, alrededor del 70 por 100 de todos los inmigrantes que iban a São Paulo y subvencionados entre el 70-90 por 100 . Incluso en el primer decenio del nuevo siglo, la mitad de los inmigrantes siguieron dirigiéndose a São Paulo y más de la mitad iban subvencionados. Las subvenciones no dejaron de desempeñar esta función predominantemente promotora hasta después de dicha fecha, e incluso después no descendió en ningún momento a menos de un tercio de todos los inmigrantes paulistas. En clara competencia con Argentina y Estados Unidos, Brasil sólo podía empezar a atraer grandes cantidades de obreros mediante el empleo de subsidios. Hasta muy entrada la década de 1910 , la migración europea no empezaría finalmente a ser autofinanciada. 
Fueron estas subvenciones y el potencial real de ahorro y acceso a la tierra los que finalmente hicieron atractivo a los trabajadores europeos el mercado de trabajo brasileño. Pese a que la colonización agrícola había llevado campesinos alemanes e italianos a las regiones meridionales de Río Grande do Sul, Santa Catarina y Curitiba en el siglo $\mathrm{xIx}$, y a que siguieron construyéndose comunidades planificadas de agricultores incluso en el siglo $\mathrm{xx}$ en Estados tan meridionales como el de Espiritu Santo, estas migraciones representaban una parte insignificante de la fuerza de trabajo nacional. Fueron los cuatro millones de africanos que llegaron a Brasil desde su fundación hasta $1850^{3}$ los que proporcionaron el mayor volumen de mano de obra agrícola para los productos de exportación cultivados en las plantaciones de azúcar, algodón y café. Estos trabajadores negros fueron a su vez complementados con una variada fuerza de trabajo mestiza. En este contexto, los inmigrantes europeos no eran sino un elemento menor en una economia en gran medida de subsistencia o regional. En fecha tan tardía como 1872, no representaban en efecto más de un 3,8 por 100 de la población nacional, y tan sólo un 3,5 por 100 de la población de São Paulo. Hacia 1900 serían un 7 por 100 de la población nacional y un impresionante 21 por 100 de la del Estado de São Paulo 4 .

En esta moderna ola de inmigración, los españoles constituyeron un elemento notable. Inmediatamente antes de 1914 habían superado en volumen a los italianos, y representaban el 22 por 100 de todos los inmigrantes venidos a Brasil (véase cuadro 1). Como los italianos, la mayor parte de los inmigrantes españoles llegaron antes de 1920, aunque habría una importante afluencia nuevamente tras la Segunda Guerra Mundial. En gran medida esta migración estaba ligada a los movimientos de la economía cafetera, y a tactores externos como fueron el estallido de la guerra europed. Por consiguiente, a partir de los datos disponibles, podría aventurarse que en el período anterior a la Primera Guerra Mundial, lo que primordialmente atrajo a los españoles hacia Brasil fueron los subsidios de transporte proporcionados por cada estado lecal y por los gobiernos federales. Así, de los 102.800 españoles que pasaron por la Hospedaria dos imigrantes de Sáo Paulo, de camino a los campos de café, entre 1910 y 1915 , sólo unos 15.630 , o un 15 por 100 , habían pagado su propio traslado 5 .

El objeto de este artículo es analizar el carácter de esta inmigración y su integración económica y social en la sociedad y la economía brasileña. Dada

\footnotetext{
${ }^{3}$ Para las estadísticas sobre el comercio de esclavos africanos con Brasil, véase Herbert S. Klcin (1987), pp. 51-59.

- Merrick y Graham (1981), p. 126, cuadro 5.3.

'Repartição de Estatística e Archivo do Estado, São Paulo (1909), 1, pp. 36-37; ibid. (1910), I, pp. 36-37; ibid. (1911), II, p. 5; ibid. (1912), 1, p. 101; ibid. (1913), 1, p. 100; ibid. (1914), I, p. 109.
} 


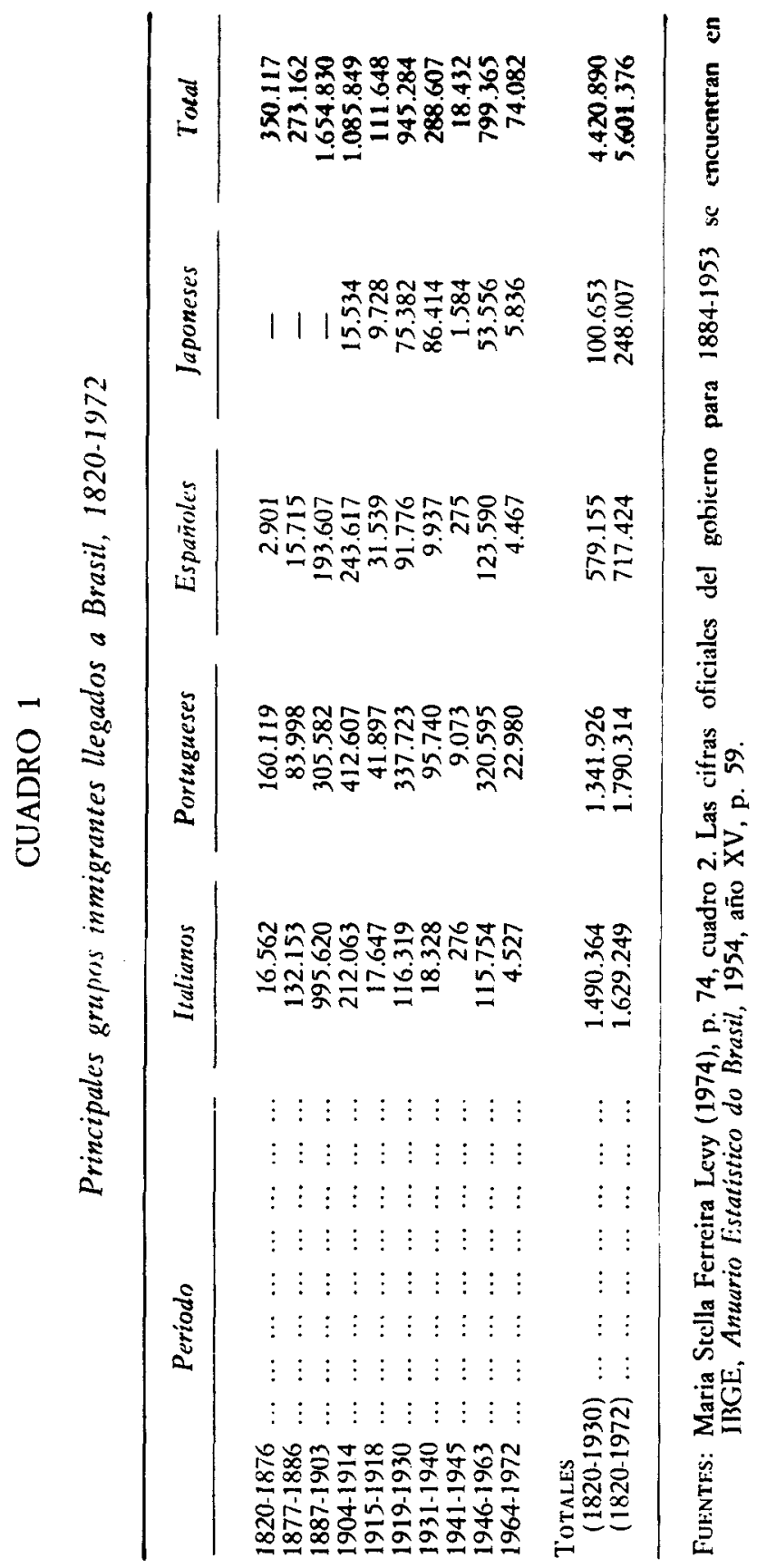


la escasez de trabajos sobre esta cuestión y las peculiaridades de las estadísticas brasileñas de inmigración ${ }^{6}$, este examen será en muchos sentidos muy prelıminar, pero es de esperar que pueda proporcionar las líneas generales básicas de la evolución de este importante grupo de inmigrantes españoles a América. Quisiera resaltar, igualmente, que las cifras que se ofrecen en este ensayo provienen todas de fuentes brasileñas, y tienden, por consiguiente, a diferir algo de los datos estadísticos de elaboración española; lo mismo ocurre con respecto a los restantes grupos extranjeros de mayor importancia ${ }^{?}$.

Como los italianos y los japoneses, los españoles fueron a Brasil primordialmente como obreros inmigrantes del café para sustituir a los esclavos liberados que abandonaban las haciendas cafeteras para convertirse en campesinos y ocupantes ilegales de las antiguas zonas cafeteras. Mientras los inmigrantes italianos y portugueses se dirigían hacia otras provincias, los españoles, como los japoneses, se concentraron ante todo en la provincia de más rápido crecimiento, corazón del cultivo del café: el Estado de São Paulo. Cuando se confeccionó el censo de 1920 , se comprobó que un 78 por 100 de los 219.142 inmigrantes nacidos en España eran residentes en dicho Estado, el porcentaje más elevado entre todos los grupos europeos ${ }^{8}$. Además, pese a haber cesado

- Las estadísticas sobre inmigración extranjera en Brasil son relativamente incompletas. Frente a la mayor parte de los restantes Estados americanos, por ejemplo, en las estadísticas brasileñas raramente se enumeran los hijos de inmigrantes de segunda generación (los nacidos en Brasil de padres extranjeros). Por consiguiente, es difícil calibrar el efecto a largo plazo de los inmigrantes extranjeros, y todas las estadísticas de inmigración que se dan aquí corresponden solamente a los nacidos en el extranjero. Otros datos que por lo general se conservan son los de las migraciones de vuelta. que, desafortunadamente, en el caso de Brasil, no van acompañados de una descomposición de los emigrantes de vuelta por país de origen. La información sobre movilidad económica está limitada primordialmente a la propiedad de fincas rurales, y no hay prácticamente estadísticas sobre la participación de ciudadanos extranjeros por país de origen en el comercio y la industria durante ningún período, al menos a nivel estatal o nacional. No existen estudios sobre la participación inmigrante en la política y la cultura, y los escasos trabajos sobre el comportamiento social y económico de los gtupos inmigrantes se han restringido en su mayoría a pequeñas comunidades rurales.

7 Por ejemplo, las discrepancias entre las estadísticas de inmigración italianas y brasileñas son considerables y no son consistentes en ninguna dirección. Véase IBGE (1958), p. 5.

- La distribución de la población de nacimiento extranjero en 1920 era como sigue:

\begin{tabular}{|c|c|c|c|}
\hline Origen & 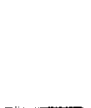 & $\begin{array}{l}\text { Porcentaje en Säo Paulo } \\
(n=\text { total de Brasil })\end{array}$ & $\begin{array}{c}\text { Porcentaje de los extranjcros } \\
\text { de São Paulo } \\
\text { ( } n=\text { total de São Paulo) }\end{array}$ \\
\hline $\begin{array}{lllll}\text { Españoles } & \ldots & & \ldots \\
\text { Italianos } & \ldots & \ldots & \ldots \\
\text { Portugueses } & \ldots & \ldots & \\
\text { Japoneses } & \ldots & \ldots & \ldots\end{array}$ & $\begin{array}{ll}\ldots & \cdots \\
\cdots & \cdots \\
\cdots & \cdots \\
\cdots & \cdots\end{array}$ & $\begin{array}{lr}78,2 & (219.142) \\
71,4 & (558.405) \\
38,6 & (433.577) \\
87,3 & (27.976)\end{array}$ & $\begin{array}{rr}20,6 & (171.289) \\
48,1 & (398.797) \\
20,1 & (167.198) \\
2,9 & (24.435)\end{array}$ \\
\hline Total $\ldots \ldots \ldots$ & $\ldots \ldots$ & $100 \quad(1.565 .961)$ & $100 \quad(829.851)$ \\
\hline
\end{tabular}

Fuente: Directoria Geral de Estatística, Recensamento do Brazil realizado em 1 de Setembro de 1920, «Populaçãom, IV, 1. ${ }^{2}$ parte, pp. 313-317. 
la inmigración subvencionada en la década de 1920 , y a la llegada ininterrumpida de inmigrantes españoles —otros 200.000 aproximadamente hasta el final de la gran inmigración de comienzos de los años 1960 — 9 , los españoles siguieron concentrándose en São Paulo. Según el censo de 1940, el 81 por 100 de los 160.557 habitantes inmigrantes oriundos de España vivía en aquel Estado ${ }^{10}$.

Es esta concentración la que convierte los documentos estadísticos de inmigración de este Estado en una importantísima fuente para conocer el carácter del inmigrante español. Siendo el único gobierno brasileño (estatal o federal) en ofrecer una clasificación de inmigrantes por edad, educación y ocupación, los datos sobre los inmigrantes españoles con destino paulista entre 1908 y 1926 son fundamentales para describir dicha población (véase cuadro 2) ${ }^{11}$.

Está claro que los españoles eran un caso poco común en este flujo migratorio, en el sentido de que era de un carácter familiar mayor que la de los inmigrantes europeos y traían consigo la mayor proporción de niños. A este respecto, eran muy parecidos a los japoneses. Pese a que entre los italianos que marchaban a Brasil había más matrimonios y llevaban más niños que ningún otro de los grupos italianos emigrados a América, seguían sin aproximarse a la notable composición familiar de la inmigración española.

Además, comparados con los restantes europeos, los españoles eran en mayor medida clasificados como trabajadores del campo, y también en esto se asemejaban más a los japoneses. Pero lo que sigue siendo aún más sorprendente es que, incluso comparados con los portugueses, fueran sin duda alguna los menos cultos de todos los grupos extranjeros llegados a Brasil en este período. No obstante esta desventaja con respecto a la educación, el hecho de que los españoles se concentraran en el Estado de más rápido crecimiento y más rico de la nación hizo que fueran afortunados a la hora de lograr acceso a la tierra. Aunque inciuso en este aspecto fueron superados por los italianos, más numerosos y llegados con anterioridad, así como por los primeros portugueses. Ya en 1905, cuando sólo habían llegado unos 230.000 inmigrantes, se comprobó que los españoles estaban concentrados como propietarios de tierras en el planalto occidental, la zona cafetera central de São Paulo donde se encontraba un 73 por 100 de las 476 fincas

\footnotetext{
- Para un total de 716.052 llegadas para 1972, a partir de la década de 1820. Véase Maria Stella Ferreira Levy (1974), pp. 71-73, cuadro 1.

${ }^{10}$ IBGE (1958), p. 17. Otra vez los japoneses, con un 91 por 100 de residentes en el Estado de São Paulo, fueron los únicos inmigrantes en aproximarse remotamente a la cifra de concentración española. Ibid., p. 40. Aunque entre 1872-1972, inicialmente, fue a São Paulo aproximadamente la misma proporción de inmigrantes italianos y españoles (Ferreira Levy [1974], p. 83, cuadro 8), los italianos parecen haberse movido mucho más, como indican las cifras de residencia resultantes de cada censo.

"Secretaria de Agricultura, Industria e Comércio, Directoria de Terras, Colonização e Immigração (DTCI), Sāo Paulo (1937), p. 74.
} 


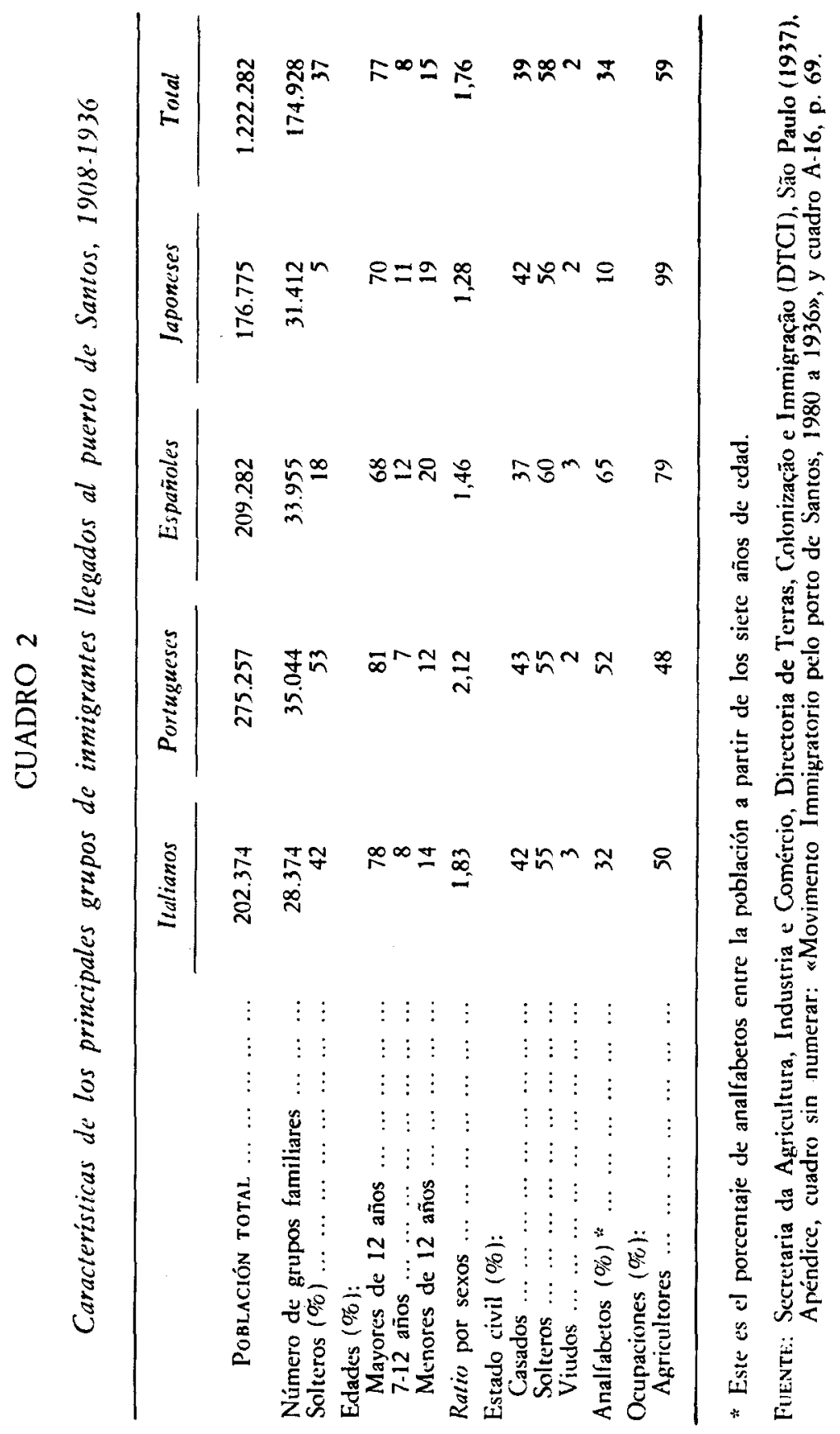


que poseían los españoles en aquel Estado. Dichas tierras representaban tan sólo un 1,1 por 100 de la tierra cultivable de esta región cafetera, siendo además, evidentemente, las tierras más marginales, dado que el valor medio de sus fincas era el más reducido; su valor total era un insignificante 0,3 por 100 de todas las haciendas de café de la región ${ }^{12}$.

Pero la ininterrumpida llegada de españoles, y su notable capacidad -como los italianos- para ahorrar, a partir de complejos contratos de trabajo, les permitió expandir sus tierras de modo continuo. Aunque caben pocas dudas de que los fazendeiros del café explotaban a los obreros subvencionados, y que muchas familias sufrieron experiencias negativas durante sus años de trabajo como colonos de las haciendas cafeteras, también es incuestionable que un número significativo de colonos logró ahorrar fondos y abandonar su condición de desposeídos de tierras. Todas las estimaciones coetáneas del promedio de ahorros, realizadas por observadores italianos, así como por posteriores historiadores, indican que con un contrato quinquenal una familia podía con facilidad obtener ahorros suficientes para comprar tierras en la locali$\mathrm{dad}^{13}$. Asimismo, como demostraron los pormenorizados estudios de Holloway sobre la propiedad de la tierra en São Paulo en 1905, todos los inmigrantes extranjeros tendieron a convertirse en pequeños terratenientes y a concentrarse en las tierras más marginales, las zonas más antiguas o las de frontera abier. $\mathrm{ta}^{14}$. Pero de un censo a otro, el valor de sus cafetos y de sus propiedades se incrementaron, hasta convertirse en serios competidores de los propietarios cafeteros nacionales ${ }^{15}$.

Hacia 1920, cuando habían llegado ya alrededor de 470.000 españoles, su acceso a la tierra había aumentado considerablemente, aunque seguía a ritmo más lento que el experimentado por los inmigrantes italianos. En 1920 estaban sólidamente establecidos en los distritos cafeteros tradicionales como propietarios (véase cuadro 3). En la totalidad del país, sódo entre los italianos era la proporción de terratenientes significativamente superior a su porcentaje del total de la población extranjera (el 45 por 100 de todos los propietarios de haciendas y sólo el 36 por 100 del total de los extranjeros). Los japoneses conseguían apenas mantenerse, y tanto entre portugueses como españoles el

12 Thomas H. Holloway (1984), pp. 222-225, cuadros 7.8.

${ }^{13}$ Zulcka M. F. Alvim (1986), pp. 93 y ss.; Holloway (1984), cap. 4.

14 Holloway (1984), cap. 6, y Kuleika M. Forcioni Alvim (1983), pp. 262 y ss., para su pormenorizado análisis de la agrimensión de tierras de 1906 y 1920 de São Paulo.

"Un buen resumen del debate en torno al éxito o fracaso de los inmigrantes italianos, en particular a la hora de adquirir la propiedad de la tierra, se encuentra en Verena Stolcke (1986), pp. 78-94. Mientras que Stolcke acepta parcialmente lo que ella denomina el modelo «optimista», cree, no obstante, que hasta muy entrada la década de 1920 los italianos no prosperaron tanto como han sostenido algunos en su paso de trabajadores sin tierra a agricultores terratenientes. 


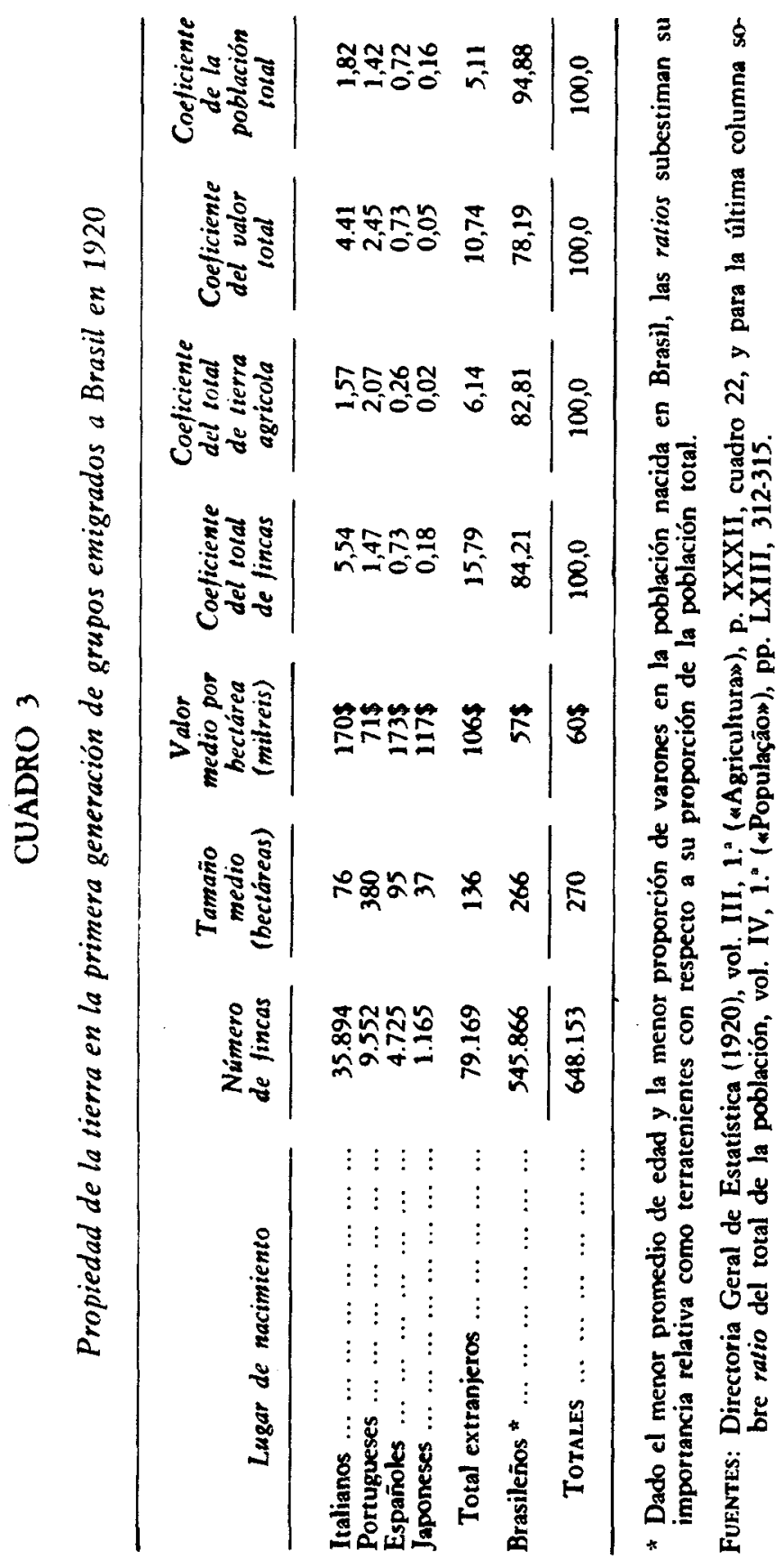




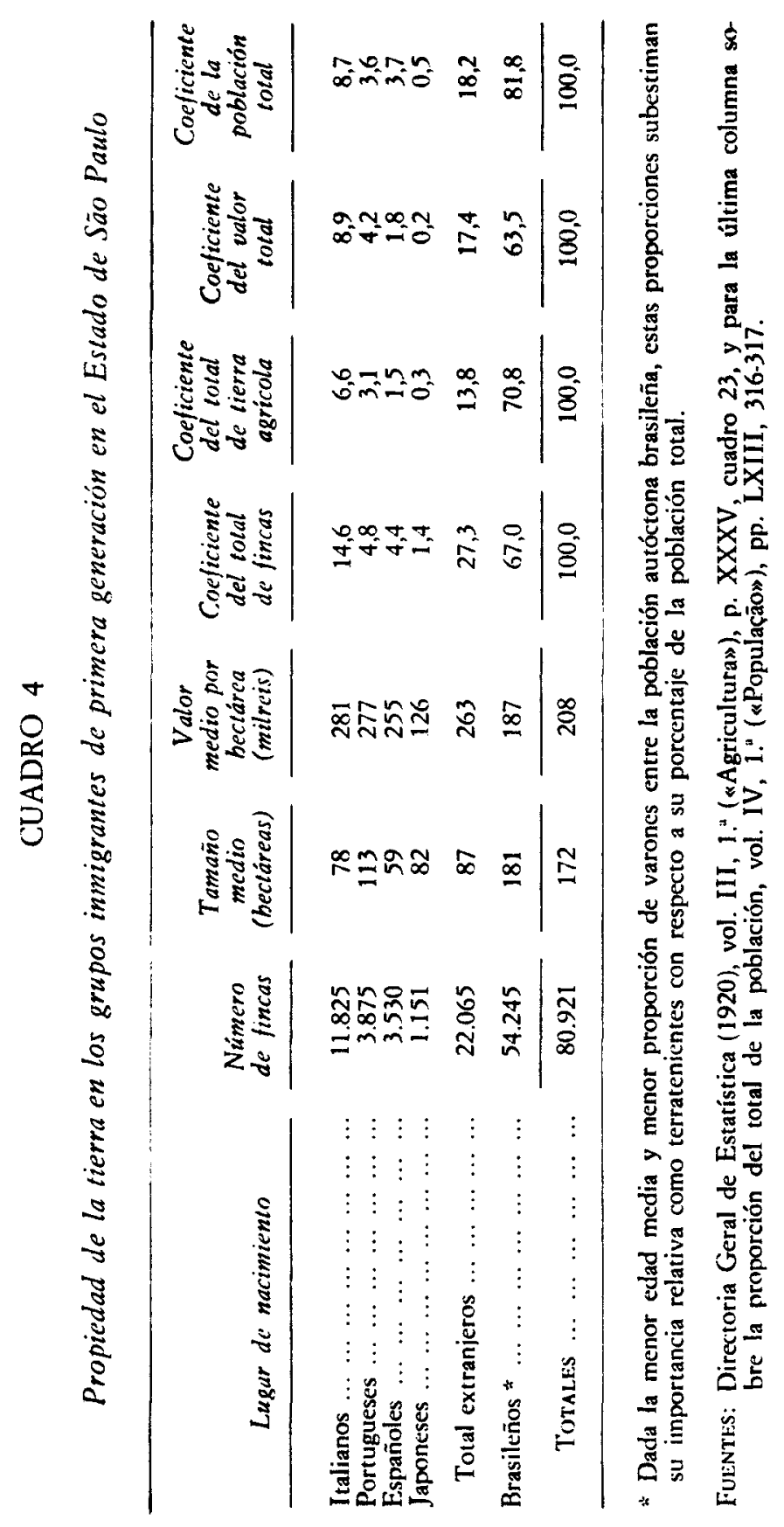


porcentaje de propietarios de tierras era inferior a la mitad de su proporción en la población total. Pero frente a los italianos, más numerosos y con más terratenientes, españoles y portugueses salieron mejor parados en cuanto a las dimensiones y riqueza de la tierra cultivable. Los españoles, de hecho. poseían el valor más alto por acre de los cuatro grandes grupos de residentes extranjeros.

Cuando estos totales nacionales se descomponen aún más, y se analizan sólo los de São Paulo, aparecen estas mismas cifras relativas, aunque parece ser que, por término medio, los españoles prosperaron al principio menos que otros inmigrantes en este Estado. Poseían una cantidad de fincas menor que el correspondiente a la importancia de su población, y el valor de sus tierras era relativamente bajo, con el resultado de que su parte de la riqueza territorial era menor que su peso entre los propietarios de tierra. Además, prosperaron menos que los portugueses, que no eran tan numerosos en este Estado ${ }^{16}$. Pero ello se debía, al parecer, a su llegada relativamente tardía a los campos de café, porque los españoles pronto superaron a sus rivales portugueses para convertirse en el segundo grupo de importancia entre los propietarios extranjeros del Estado.

Durante la enorme expansión de la industria del café a comienzos de los años 1920, los inmigrantes extranjeros siguieron ascendiendo no sólo como propietarios, sino también como productores de café. En 1923, un 32 por 100 de los cafetos en producción de la zona cafetera más rica de Brasil, los llanos paulistas occidentales, eran propiedad de extranjeros. Ni siquiera los efectos de la Gran Depresión consiguieron aminorar esta expansión, porque en 1932 los inmigrantes nacidos en el extranjero habían incrementado su parte proporcional en la propiedad de la tierra hasta un 39 por 100 de todos los cafetos de la zona, y los españoles habían aventajado a los portugueses, convirtiéndose en el segundo grupo en importancia de propietarios forasteros, con un 6 por 100 de todos los árboles.

En los años inmediatamente siguientes, la proporción de la propiedad en manos de extranjeros ascendió aún más. En un censo especial del Estado de 1934, los forasteros habian incrementado su control sobre los 1,5 millones de cafetos hasta un 42 por 100 , y la continua expansión de la riqueza de los españoles inmigrantes (que poseían ya el 7,4 por 100 de todos los cafetos) les mantuvo en segundo lugar después de los italianos. Más aún, a diferencia de 1920 , su peso relativo como propietarios de haciendas cafeteras y productores de café excedía con mucho su porcentaje de la población total del Estado de São Paulo, por un factor de tres (véase cuadro 5). En realidad,

16 Eran un 20,6 por 100 de la población total y solamente un 16 por 100 de los propietarios. Directoria Geral de Estatística, 1V, 1.2, pp. 313-317. 


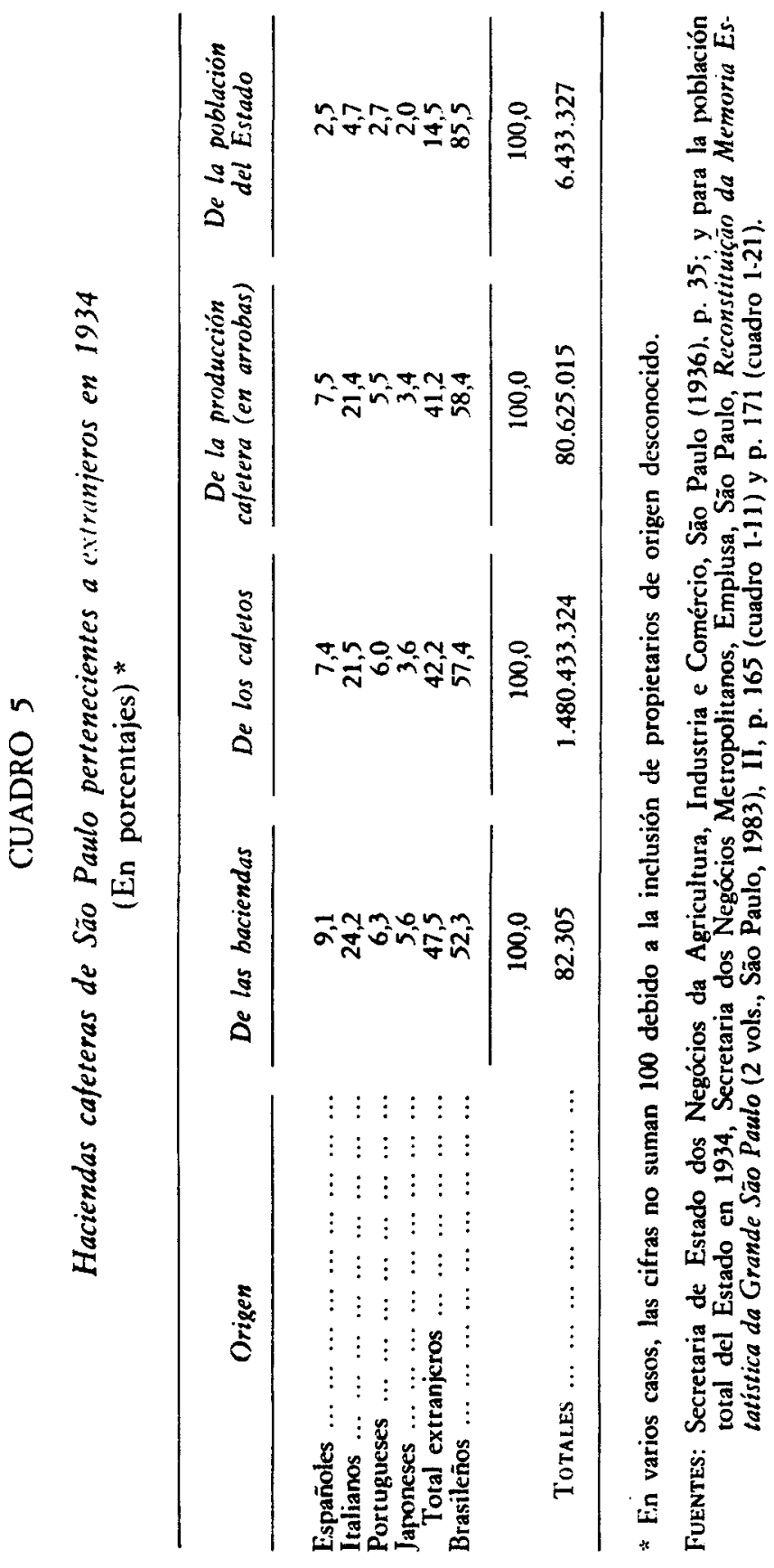


los españoles consiguieron una posición relativamente buena en la producción de casi todos los géneros alimenticios, aunque en menor grado que en el café - del orden del 5-6 por 100 en la mayoría de los cultivos-. Pero en el São Paulo de 1934, su importancia relativa con respecto a tres productos era sobresaliente: la cebolla (con un 26 por 100 de las tierras y 36 por 100 de la producción total); naranjas ( 8 por 100 de las tierras y 13 por 100 de la producción del Estado, y plátanos (con 7 por 100 de las tierras y 12 por 100 de la producción) ${ }^{17}$.

Los españoles, cuya tendencia era a gravitar hacia las grandes áreas de producción del São Paulo rural, eran los menos urbanos de los principales grupos europeos. En el censo estatal de 1934, el 50 por 100 de los extranjeros vivían en centros urbanos, mientras que sólo un 42 por 100 de los españoles se instalaron en ellos. El porcentaje de residentes rurales era la cifra más elevada entre los grandes grupos europeos, sólo superada por el caso especial de los japoneses ( 92 por 100). Además, aunque los españoles formaban el tercer grupo de inmigrantes en la ciudad de São Paulo, al igual que los japoneses, parecían preferir centros urbanos secundarios a la capital del Estado ${ }^{18}$.

Ello podría explicar a su vez el por qué los españoles tienen relativamente poca importancia en las escasas muestras de participación en la fuerza laboral urbana de que disponemos. Por ejemplo, en 1911, en que un 59 por 100 de los 10.204 obreros textiles de Sāo Paulo eran oriundos de Italia, los españoles representaban tan sólo un 3 por 100 del total. De los 2.299 obreros empleados por este Estado en aquel mismo año, los españoles suponían un 7 por 100 de la fuerza de trabajo, muy por debajo tanto de italianos como de portugueses ${ }^{19}$. Es cierto que la historia del proceso inmigratorio estaba en sus primeras etapas, y que su importancia relativa debió incrementarse considerablemente, especialmente con el rápido crecimiento de la industria en los grandes centros del Estado. Hacia 1919, en el Estado de São Paulo se concentraba el 32 por 100 de las industrias brasileñas - habiendo ascendido a esta proporción desde el 15 por 100 de $1909-$ y dicha concentración seguiría en aumento en años posteriores ${ }^{20}$. Pese a todo, parece ser que los inmigrantes españoles no realizaron nunca intentos serios de acceso a la propiedad de las industrias paulistas. Un estudio de estas industrias en la década de 1970 puso de manifiesto que los españoles, hasta la tercera generación,

${ }^{17}$ Secretaria de Estado dos Negocios da Agricultura, Industria e Comércio, São Paulo (1936), pp. 36 y ss.

${ }_{18}$ Departamento Estadual de Estatística, São Paulo (1939), pp. 76-77.

19 Departamento Estadual do Trabalho, São Paulo (1911-1912), pp. 74.75 y pp. 120-121.

20 Wilson Cano (1983), p. 192, cuadro 23. De los aproximadamente 760.000 trabajadores varones empleados en la industria brasileña en 1920, un 23 por 100 habian nacido en el extranjero. Directoria Geral de Estatistica (1920), p. XV. 
representaban solamente el 3,8 por 100 de los directores de empresas de 250 obreros o más en la región metropolitana del Gran São Paulo, frente al 31 por 100 de ascendencia italiana, el 10 por 100 de abuelos o padres portugueses, o nacidos en Portugal, y el 20 por 100 de origen brasileño (con al menos abuelos nacidos en Brasil). Igualmente, entre los propietarios de compañías de São Paulo de 100 o más trabajadores, los inmigrantes de origen extranjero de primera, segunda o tercera generación y sus herederos controlaban el 73 por 100 de estas compañías, constituyendo los italianos el mayor grupo étnico. Sin embargo, los españoles de primera y sucesivas generaciones representaban menos del 2 por 100 de los propietarios de dichas empresas ${ }^{21}$. La impresión general que se extrae sobre la trayectoria ocupacional de los españoles es que se concentraron primordialmente en la propiedad de fincas rústicas y en actividades comerciales en el interior de las ciudades y la capital. Son los portugueses - los más urbanos de los inmigrantes- y los italianos, los que parecen haber tenido mayor importancia en la fuerza de trabajo urbana; y eran los italianos los más dispuestos, al parecer, a hacerse con el control del sector industrial.

Las especiales características observadas en los españoles llegados a Santos en la primera mitad del siglo $\mathrm{xx}$, tuvieron también su efecto en aquellos que accedieron al mercado matrimonial en el Estado de São Paulo durante la década de 1910 (véase cuadro 6). Dada la elevada proporción de mujeres entre estos inmigrantes (sólo igualada por los japoneses), no es extraño que, dentro del grupo de los que contrajeron matrimonio, los españoles destaquen por su bajísima tasa de nupcialidad (1,11, frente a 1,69 o más de los restantes grupos de inmigrantes enumerados en el cuadro 6). Ahora bien, lo que es aún más sorprendente es la gran proporción de endogamia marital de los españoles, lo cual les singularizaba entre los inmigrantes europeos. Mientras que un 33 por 100 de los españoles se casó con sus paisanos, la proporción entre los italianos era del 21 por 100 y entre los portugueses de sólo el 27 por 100 . Y más sorprendente todavía es que mientras que el matrimonio exogámico era corriente entre los varones nacidos en el extranjero (sólo un 34 por 100 de italianos contrajo matrimonio con italianas; y solamente un 43 por 100 de los portugueses), y menos frecuente entre las extranjeras, en el caso de los españoles, tanto hombres como mujeres, se casaron dentro de su grupo étnico en proporción parecida (62 por 100 de los españoles se casaron con españolas y 69 por 100 de las españolas se casaron con españoles) ${ }^{22}$. Claramente, el hecho de proceder de un medio más analfabeto y de índole campesino se

${ }^{21}$ Luis Carlos Bresser Pereira (1974), p. 73, cuadro XIII; p. 78, cuadro XVI, y pp. 198.200 y Apéndice cuadro 4 .

${ }^{22} \mathrm{La}$ cifra de mujeres italianas que se casaban con sus compatriotas era del 57 por 100 y la de mujeres portuguesas era muy superior, de un 75 por 100 . 


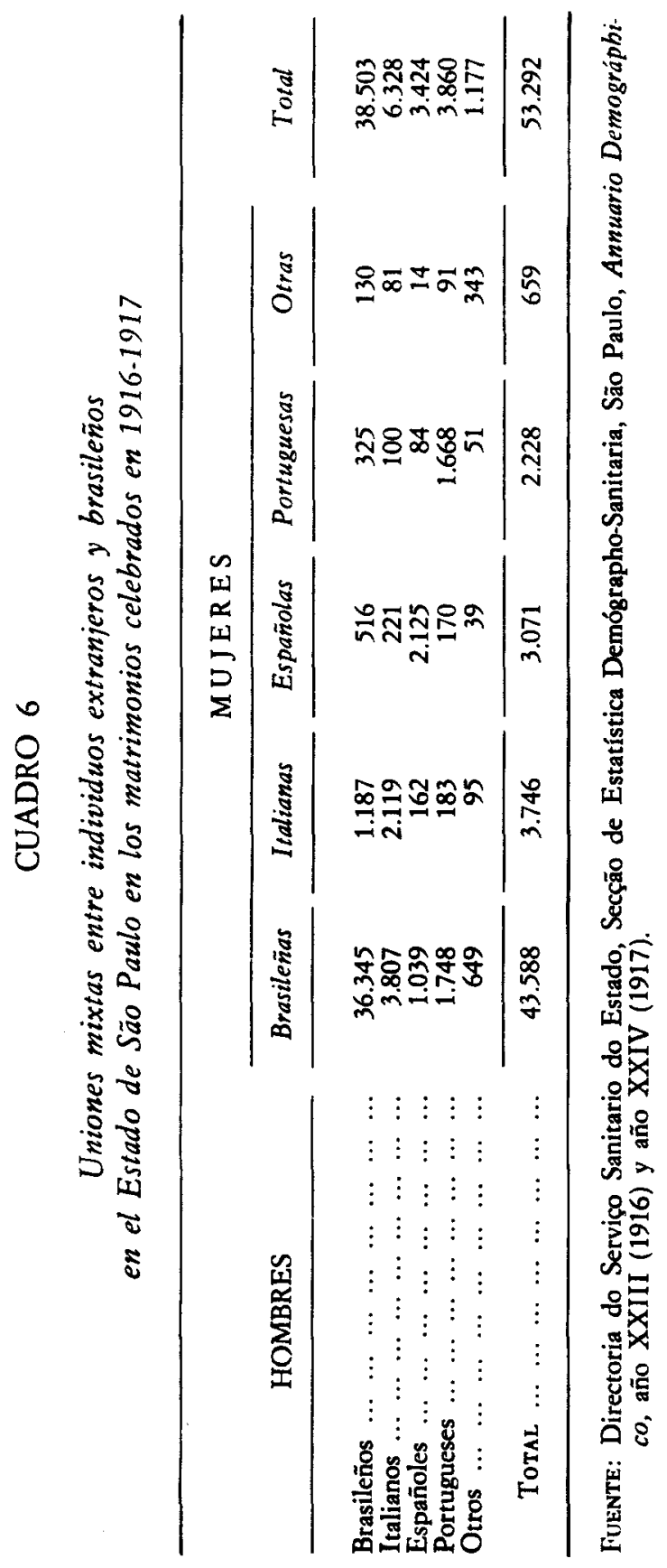


manifestaba en una mayor propensión hacia la endogamia, incluso entre los hombres. Por el contrario, pese a que las mujeres portuguesas, intensamente tradicionales, se casaron en tres cuartas partes de los casos con sus paisanos, menos de la mitad de los portugueses lo hicieron. En éste, como en tantos otros aspectos, sólo los japoneses superaron a los españoles. Aunque fueron muy pocos los japoneses que contrajeron matrimonio, posteriores estudios hallaron que de 1908 a 1962 había un índice de endogamia increíblemente alto entre los inmigrantes japoneses (sólo un 3 por 100 de los 38.729 hombres que se casaron en este período y apenas un 0,3 por 100 de las 30.205 mujeres lo hicieron con no japoneses) ${ }^{23}$.

Pero la progresiva educación y urbanización de los inmigrantes españoles impuso pronto un significativo cambio en las pautas de integración. En 1926, por ejemplo, entre los 4.093 hombres y mujeres nacidos en España que contrajeron matrimonio en todo el Estado de São Paulo en aquel año, el porcentaje que lo hizo con sus compatriotas descendió al 24 por 100; y no sólo había bajado al 50 por 100 la proporción de hombres en matrimonios endogámicos, sino que también las mujeres españolas se casaron con españoles en sólo un 46 por 100 de los casos ${ }^{24}$. Esta tendencia hacia la integración en la cultura brasileña se hizo aún más patente al compilar los datos sobre todos los matrimonios celebrados en la ciudad de São Paulo en el período de 19341946. Alli, durante un momento de inmigración muy escasa, entre los 5.232 españoles que contrajeron matrimonio el índice de endogamia fue simplemente del 12 por 100 , con sólo un 20 por 100 de españoles unidos por matrimonio a españolas y un 30 por 100 de españolas unidas a españoles. En este caso, y por primera vez en la compilación de estadísticas matrimoniales de São Paulo, tanto españoles como españolas se casaron con brasileños más que con sus propios compatriotas (véase cuadro 7). No deja de ser interesante que en ésta y sucesivas estadísticas fueran los portugueses - reforzados por grandes cantidades de nuevos inmigrantes en los años treinta y cuarentalos que representaron el grupo más endogámico entre los europeos.

Pese a que en los primeros decenios los españoles mostraran muchas características en común con los japoneses, sus compañeros de trabajo en los cafetales, en otros aspectos era más lo que les asemejaba a sus compañeros europeos de emigración desde un principio. En el ámbito de la migración de vuelta a Europa, eran tan adeptos a la idea de volver a la patria para iniciar una nueva vida como los italianos, que retornaban de forma continua.

${ }^{23}$ Incluso los hijos de inmigrantes conservaron esta característica: según un estudio de 1958-1962, sólo un 18 por 100 de los niños de padres japoneses contraían matrimonio con no japonesas, y sólo un 8 por 100 de las mujeres de segunda generación. Véase Co. missão de Recenseamento da Colônia Japonesa (1964), p. 356, cuadro 276.

24 Serviço Sanitario do Estado, São Paulo (1926), I, p. 33; II, p. 917. 


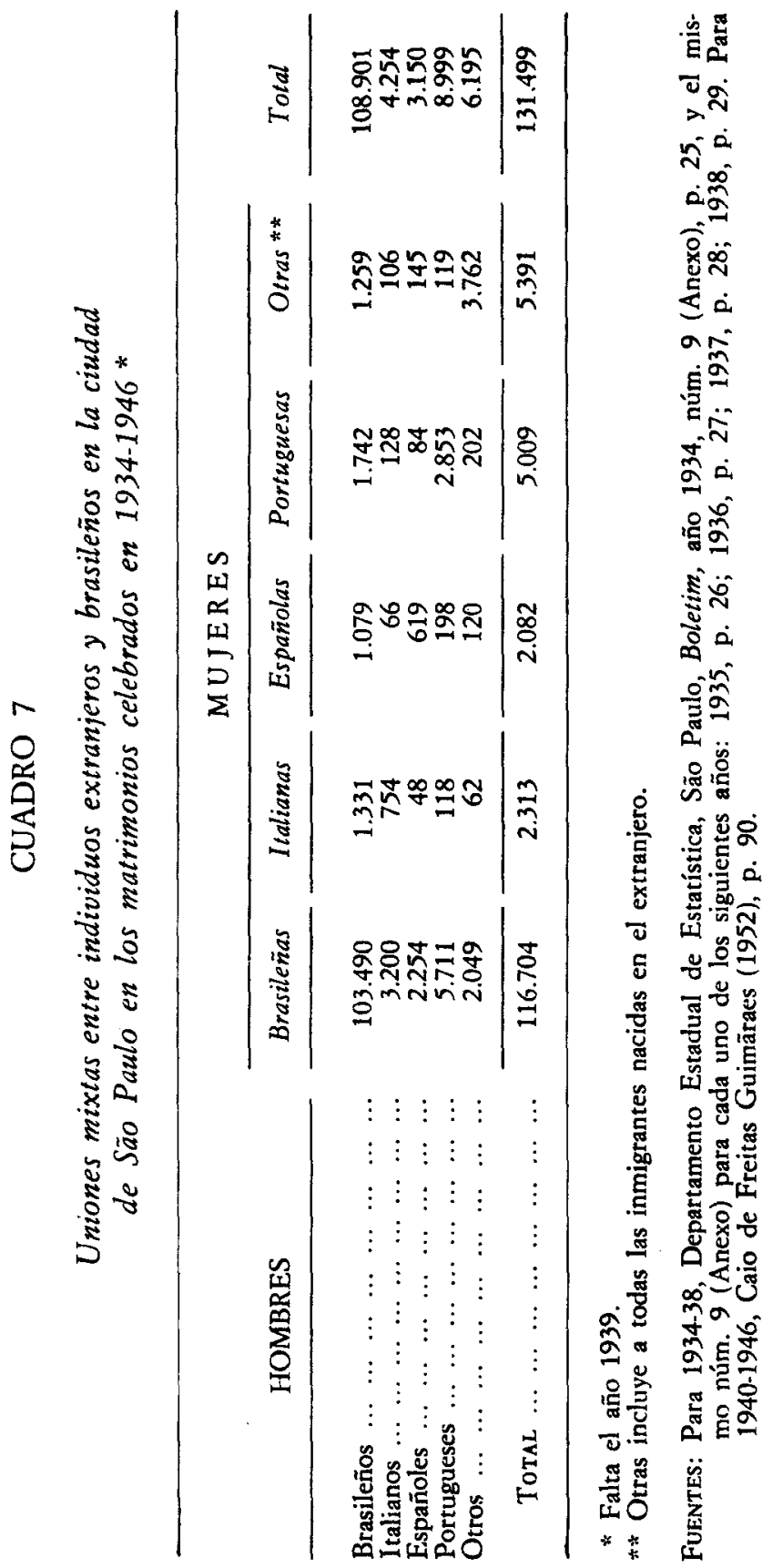


Dada la capacidad de los inmigrantes españoles para regresar a Europa, o emigrar a otros países latinoamericanos, la inmigración española en Brasil se mostró tan sensible a las crisis económicas como otras inmigraciones europeas. Todos los estudios demuestran que cualquier descenso en los precios del café quedaba inmediatamente registrado en un mayor índice de emigración de vuelta y en un descenso correspondiente en la llegada de inmigrantes. Además, las recientes estimaciones de Ferreira Levy han corregido en sentido descendente los elevados índices de permanencia elaborados primeramente por Grigorio Mortara, el cual calculó que casi el 70 por 100 de los inmigrantes llegados se quedaba. Frente a ello, Ferreira Levy ha calculado un índice de permanencia del 64 por $100, y$ ha determinado que, de hecho, los inmigrantes españoles tenían el segundo índice más alto de permanencia después de los italianos, para los que Mortara había calculado previamente una emigración de vuelta del 50 por $100^{25}$.

Como hace patente este análisis preliminar, la emigración española a Brasil fue, en sus primeras fases, un caso muy especial entre las migraciones europeas, pues llevó al país un flujo de inmigrantes que en su mayor parte se trataba de unidades familiares, y que traían consigo a un gran número de niños. Estos trabajadores agrícolas no especializados eran los menos cultos de todos los grandes grupos llegados de Europa, hecho que, sin embargo, compensaron rápidamente al ascender social y económicamente. La tierra parece haber sido el principal objetivo de la primera generación, y hacia la década de los años treinta los españoles constituían una fuerza dominante en la agricultura paulista. En grado sorprendente, los inmigrantes españoles se asemejaban más a sus compañeros japoneses que a ningún otro grupo. Pero la progresiva movilidad económica de estos inmigrantes, que se manifestaba en su acceso a la propiedad de tierras, pronto se plasmó también en una creciente integración social. Mientras que los inmigrantes españoles de los años 1910 habian sido los más endógamos de todos los llegados de Europa, y los segundos en términos de natalidad ${ }^{26}$, a fines de los años treinta se estaba produciendo una aculturación e integración rápida con la población nativa brasileña. Empleando los datos sobre matrimonios para el período de 1934-1946, se hizo evidente que por aquel entonces los españoles ya no se diferenciaban de los restantes grandes grupos y estaban perdiendo rápidamente su identidad étnica y su individualidad.

${ }^{25}$ G. Ferreira Levy (1974), pp. 62-67; Mortara (1950), p. 325.

${ }^{26}$ Ferreira Levy (1974), p. 67. 


\section{APENDICE}

\section{CUADRO 1}

Inmigración española a Brasil y São Paulo, 1872-1972 (Por quinquenios)

\begin{tabular}{|c|c|c|}
\hline Periodo & Total Brasil & São Paulo \\
\hline $\begin{array}{lllllll}1872-1877 & \ldots & \ldots & \ldots & \ldots & \ldots & \ldots \\
1878-1881 & \ldots & \ldots & \ldots & \ldots & \ldots & \ldots \\
1882-1884 & \ldots & \ldots & \ldots & \ldots & \ldots & \ldots \\
1885-1889 & \ldots & \ldots & \ldots & \ldots & \ldots & \ldots \\
1890-1894 & \ldots & \ldots & \ldots & \ldots & \ldots & \ldots \\
1895-1899 & \ldots & \ldots & \ldots & \ldots & \ldots & \ldots \\
1960-1904 & \ldots & \ldots & \ldots & \ldots & \ldots & \ldots \\
1905-1909 & \ldots & \ldots & \ldots & \ldots & \ldots & \ldots \\
1910-1914 & \ldots & \ldots & \ldots & \ldots & \ldots & \ldots \\
1915-1919 & \ldots & \ldots & \ldots & \ldots & \ldots & \ldots \\
1920-1924 & \ldots & \ldots & \ldots & \ldots & \ldots & \ldots \\
1925-1929 & \ldots & \ldots & \ldots & \ldots & \ldots & \ldots \\
1930-1934 & \ldots & \ldots & \ldots & \ldots & \ldots & \ldots \\
1935-1939 & \ldots & \ldots & \ldots & \ldots & \ldots & \ldots \\
1940-1944 & \ldots & \ldots & \ldots & \ldots & \ldots & \ldots \\
1945-1949 & \ldots & \ldots & \ldots & \ldots & \ldots & \ldots \\
1950-1954 & \ldots & \ldots & \ldots & \ldots & \ldots & \ldots \\
1955-1959 & \ldots & \ldots & \ldots & \ldots & \ldots & \ldots \\
1960-1964 & \ldots & \ldots & \ldots & \ldots & \ldots & \ldots \\
1965-1969 & \ldots & \ldots & \ldots & \ldots & \ldots & \ldots \\
1970-1972 & \ldots & \ldots & \ldots & \ldots & \ldots & \ldots\end{array}$ & $\begin{array}{r}1.552 \\
5.792 \\
7.331 \\
18.738 \\
89.609 \\
74.684 \\
23.146 \\
90.086 \\
143.485 \\
38.166 \\
44.906 \\
37.025 \\
9.751 \\
3.175 \\
610 \\
4.092 \\
55.874 \\
38.819 \\
25.495 \\
2.902 \\
949\end{array}$ & $\begin{array}{r}\text { n. d. } \\
\text { n. d. } \\
694 \\
4.843 \\
42.316 \\
44.678 \\
18.842 \\
69.682 \\
108.154 \\
27.172 \\
36.502 \\
27.312 \\
4.876 \\
1.708 \\
181 \\
1.136 \\
34.256 \\
28.040 \\
12.942 \\
86 \\
177\end{array}$ \\
\hline Total $\ldots \ldots \ldots \ldots \ldots$ & 701.377 & 462.885 \\
\hline
\end{tabular}

Nota: n. $\mathrm{d}=$ no disponible.

FuenTE: Ferreira Levy (1974), p. 83, cuadro 8. 


\section{BIBLIOGRAFIA}

Alvim, Zuleka M. F. (1986): Brava Gente! Os italianos em São Paulo, 1870.1920, São Paulo.

- (1983): «Emigração, Família e Luta: Os italianos em São Paulo, 1870-1920» (Diss. de Maestrado, USP.FELCH, Departamento de Historia).

Bresser Pereira, Luis Carlos (1974): Empresarios e administradores no Brasil, São Paulo.

Camargo, José Francisco de (1981): Crescimento da populaçāo no estado de São Paulo $e$ sus aspectos econômicos, São Paulo $\left(2{ }^{2}\right.$ ed., 3 vols., FIPE/USP, Ensaios Econômicos, núm. 14).

Cano, Wilson (1983): Raizes da concentraçāo industrial em São Paulo (2." ed.), São Paulo.

Comissão de ReCEnSEamento da Colónia JaPonesa (1964): The Japanese Immigrant in Brazil, Tokyo, University of Tokyo Press.

Departamento Estadual de Estatística, São Paulo (1939): Boletim, núm. 1.

Departamento Estadual do Trabalho, São Paulo (1911-1912): «Condiçãoes do trabalho na indústria têxtil no estado de São Paulo", Boletim, año I, núms. 1-2.

Directoria Geral de Estatística (1920?): Recensamento do Brazil realizado em 1 de Setembro de 1920, IV.

Ferreira Levy, Maria Stella (1974): «O papel da migração internacional na evolução da populaçāo brasileira (1872 a 1972)», Revista de Saúde Pública, 8 (Supl.).

Freitas GuImarãs, C. (1952): "A assimilação dos principais grupos estrangeiros atraves das estatísticas dos casamentos e nascimentos, na populaçāo do Municipio de São Paulo, 1940/46», Boletim Especial, año XIV, 2." fase, núm. 1.

Holloway, Thomas H. (1984; edición inglesa, 1980): Imigrantes para o café. Café e sociedade em Säo Paulo, 1886-1934, Río de Janeiro.

IBGE (1958): Alguns dados sôbre a emigração italiana para o Brasil, Río de Janeiro.

- (1958): A distribuição territorial dos estrangeiros no Brasil (Estudos de estatística teórica e aplicada), Río de Janeiro.

KLEin, Herbert S. (1987): "Tráfico de Escravo», en IBGE, Estatisticas Históricas do Brasil, Río de Janeiro.

Merrick, Thomas W., y Graham, Douglas H. (1981; edición inglesa, 1979): População e desenvolvimento económico no Brasil, Río de Janeiro.

Mortara, Grigorio (1950): «A imigração italiana no Brasil e algunas características do grupo italiano de São Paulom, Revista Brasileira de Estatistica, 11.

Repartiça de Estatística e Archivo do Estado (1909): Anuario estatístico de São Paulo, 1909-1914, núms. I-II.

Secretaria de Agricultura, Industria e Comércio, Directoria de Terras, Colonização e Immigração (DTCI) (1937): Boletim, año I, núm. 1.

Secretaria de Estado dos Negócios da Agricultura, Industria e Comércio (1936): Recenseamento agricola-zootechnico realizado em 1934, São Paulo.

Serviço Sanitario do Estado (1926): Annuario Demograpbico, año XXXII, I, y II.

StolCKe, Verena (1986): Cafeicultura, homes, mulberes e capital (1850-1980), São Paulo. 